\section{Are intermediate vectors needed between foreign DNA on sperm and the nucleus?}

The recent article by Lavitrano et al. ${ }^{1}$ on producing transgenic mice using in vitro fertilization with sperm exposed to foreign DNA attracted much attention but it has not been confirmed 2 . Lavitrano et al. ${ }^{3}$ have not been able to suggest reasons for the discrepant results. I would like to suggest such a reason. Although preimplantation embryos support SV40 infection ${ }^{4}$ and SV40 DNA injected into preimplantation embryos may integrate into the host genome the incomplete genome of SV40 in pSV2CAT should not be replication competent. However, preimplantation embryos show a remarkable activation of intracisternal A particles ${ }^{6-9}$; these retroviral particles incorporate functional reverse transcriptase ${ }^{10}$ but only bud internally into the endoplasmic reticulum and do not infect other cells. They and other retroviral particles might reverse transcribe the SV40 transcript and insert it in the genome. In fact, the embryonic retroposon activity at this stage of development may be selected by evolution - active retroposon-captured pseudogenes are at least important for spermatogenesis"11. If, indeed, intracisternal A or other viral activities of preimplantation embryos, or even sperm ${ }^{12}$, mediated reverse transcription and integration of SV40 sequences from the vector, several puzzling aspects of the data of Lavitrano et al!' might be explained: (1) the uniform size of integrants and (2) the loss of restriction sites at both junctions between vector and insert DNA. Variation in the endogenous retroviral activities among different colonies and strains of mice might explain failed attempts to replicate the work ${ }^{2}$.

To be experimentally useful, a method for production of transgenic mice must lead not only to integration of the foreign sequences but also to their expression. Lavitrano et al. used the chloramphenicol acetyltransferase (CAT) gene as the reporter gene in their studies. The likelihood of expression of the SV40-CAT integrant would depend on the extent and fidelity of the reverse transcript and the site where it integrated. In fact, the need to incubate the CAT assays overnight, instead of the usual few hours, and the finding that one of the two positive tissues was 'tail', with its high probability of being contaminated with feces, suggests that the apparent expression from the foreign DNA might have been due to bacterial growth. The low level of CAT activity would also fit the contamination hypothesis.
In conclusion, the basis for integration events, but not transgene expression, in the work by Lavitrano et al. ${ }^{1}$ may be explained by retrotransposon-like events.

\section{RoberT P. ERICKSON}

D1109 MPB, Bax 0718, University of Michigan School of Medicine, Ann Arbor, MI 48109-0718, USA.

\section{References}

1 Lavitrano, M. et al. (1989) Cell 57, $717-723$

2 Brinster, R.L. et al. (1989) Cell 59, 239-241

3 Lavitrano, M. et al. (1989) Cell 59 , 241

4 Ambramczuk, J., Vorbrodt, A., Solter, D. and Koprowski, H. (1978) Proc Natl Acad. Sci. USA 75, 999-1003

5 Jaenisch, R. and Mintz, B. (1974) Proc. Natl Acad. Sci. USA 71, 1250-1254

6 Calarco, P.G. and Szollosi, D. (1973) Nature New Biol. 243, 91-93

7 Yotsuyanagi, Y. and Szollosi, D. (1981) J. Natl Cancer Inst. 67, 677-685

8 Piko, L., Hamnond, M.D. and Taylor, K.D. (1984) Proc. Natl Acad. Sci. USA 81, 488-492

9 Weng, D.E., Morgan, R.A. and Gearhart, J.D. (1989) Mol. Reprod. Dev. 1, 233-241

10 Yang, S.S. and Wivel, N.A. (1976) Biocbim. Biophys. Acta 444, 167-174

11 McCarrey, J.R. and Thomas, K. (1987) Nature 326, 501-505

12 Kiessling, A.A., Crowell, R.C. and Connell, R.S. (1987) Proc. Natl Acad. Sci. USA 84, 8667-8671

method of choice unless the contaminated surface is likely to be damaged by the acidic decontamination solution.

\section{GeorGe LUNN} it forms fluorescent complexes by intercalacion.

A Technical Tip ${ }^{1}$ based on our published method ${ }^{2}$ for decontamination of ethidium bromide (EB) solutions (by treatment with sodium nitrite and hypophosphorous acid) provoked correspondence from readers ${ }^{3-5}$ on different methods for destroying EB, and on the problem of how to deal with EB spills on laboratory surfaces and equipment such as transilluminators. We have found ${ }^{6}$ that EB can be removed from stainless steel, Formica, vinyl floor tile, glass, and the filters of transilluminators by wiping the surface once with paper towels containing a decontamination solution of sodium nitrite and hypophosphorous acid, and five times with paper towels wet with water. No traces of EB remained in the washing, and the optical properties of the transilluminator filters were unimpaired. A red stain (which could have been EB or a degradation product) remained on the floor tile, but no more EB could be removed by further washes. EB could also be effectively removed from all the surfaces by wiping six times with wet paper towels only, though both the Formica and the floor tile remained stained, and the paper towels used were contaminated with undegraded EB. All paper towels used in either procedure should be soaked in fresh decontamination solution before disposal. In our view, the first method we have described should be the

\section{National Cancer Institute, Frederick Cancer} Researcb Facility, PO Box B, Frederick, MD 21701, USA.

\section{References}

1 Trends Genet. 3, 176 (1987)

2 Lunn, G. and Sansone, E.B. (1987) Anal. Biochem. 162, 453-458

3 Cohen, B.L. (1987) Trends Genet. 3, 308

4 Quillardet, P. and Hofnung, M. (1988) Trends Genet. 4, 89

5 Bensaude, O. (1988) Trends Genet. 4, 89

6 Lunn, G. and Sansone, E.B. (1989) Appl. Ind. Hyg. 4, 234-237

(Reprints of Ref. 6 are available from the authors on request.) 